\title{
Discrimination of metamorphic diamond populations by Raman spectroscopy (Kokchetav, Kazakhstan)
}

\author{
Andrey V. Korsakov ${ }^{a}{ }^{a}$, Peter Vandenabeele $^{b}$, Karel Theunissen ${ }^{c}$ \\ ${ }^{a}$ Institute of Mineralogy and Petrography of Siberian Branch Russian Academy of Sciences, Koptyug Pr. 3, Novosibirsk 630090, Russia \\ ${ }^{\mathrm{b}}$ Ghent University, Department of Analytical Chemistry Raman Research Group, Proeftuinstraat 86, B-9000 Ghent, Belgium \\ ${ }^{c}$ Department of Geology and Mineralogy, Royal Museum for Central Africa, B-3080 Tervuren, Belgium
}

Received 10 June 2004; accepted 4 February 2005

\begin{abstract}
Metamorphic diamond is a powerful but frequently debated indicator for ultrahigh-pressure metamorphic (UHPM) conditions. Because of their small size, their optical identification needs confirmation. Characteristics of chemically extracted microdiamonds from Kokchetav, identified by different analytical methods, are used here for unambiguous in situ identification by Raman microspectroscopy. Differences appear in the diamond spectra and the Raman analytical method is explored as a helpful tool in the discrimination between diamond populations from four different UHPM lithologies of Kokchetav. Not considering the graphite-coated diamond, out of the reach of the laser wavelength used here, the comparison of these Kokchetav Raman spectra may provide additional information in other UHPM studies.
\end{abstract}

(C) 2005 Elsevier B.V. All rights reserved.

Keywords: Microdiamond; Raman; UHPM rocks; Kokchetav massif

\section{Introduction}

Raman microspectroscopy is a non-destructive analytical method providing an opportunity to unambiguously distinguish micro-sized particles of mineral polymorphs [1]. The method is now increasingly used in ultrahigh-pressure metamorphic (UHPM) petrology for the in situ identification of coesite relics or diamond inclusions in their host mineral [2-13]. Recently, new Raman spectroscopy techniques were used in mapping the quartz-coesite phase transformation in a $\mathrm{SiO}_{2}$ inclusion in clinopyroxene from Himalayan eclogites [14].

Metamorphic diamond is a powerful index mineral for UHPM conditions. Because their generally small size, the optical identification of metamorphic diamonds from the Erzgebirge have only recently been discovered [15], and their characteristic Raman spectra were quickly published as confirmation [7]. Such convincing information is still lacking for Kokchetav, where microdiamonds were identified about 30 years ago [16] and were shown to occur as inclusions in meta-

\footnotetext{
* Corresponding author. Tel.: +7 38323325 17; fax: +7 3832332792

E-mail address: korsakov@uiggm.nsc.ru (A.V. Korsakov).
}

morphic minerals [17]. It is a first aim of this paper to present the Raman spectra of Kokchetav microdiamonds.

Kokchetav microdiamonds have been widely investigated by other analytical methods and it has been shown that their morphology, nitrogen impurities and inclusion contents change depending on the lithology [18-21]. Assuming that these changes in their characteristic properties should also be reflected in their Raman spectra, it is the second aim of this work to attempt to discriminate distinct diamonds from different rock types of the Kokchetav massif, by means of Raman spectroscopy. The comparison of these Kokchetav data with diamond spectra from Erzgebirge, Norway and from other diamond-bearing regions, including the recently reported occurrence in central China [22], may further document and provide complementary information on particular conditions favoring such metamorphic diamond occurrences.

\section{Analytical conditions and sample preparation}

Dispersive laser-Raman spectra were obtained by means of a Renishaw (Wotton-under-Edge, UK) System-1000 spec- 
trometer equipped with a $785 \mathrm{~nm}$ diode laser $(50 \mathrm{~mW})$, a 1200 lines/mm diffraction grating and a Peltier-cooled CCD detector. The spectrometer contains an Olympus BH-2 microscope, with $5 \times, 20 \times, 50 \times$ and $80 \times$ objective lenses, enabling us to reach a lateral resolution down to $1 \mu \mathrm{m}$.

Raman mapping was performed by means of a fibercoupled Kaiser Optical Systems (Ecully, France) spectrometer, equipped with a powerful diode laser (ca. $300 \mathrm{~mW}$, Toptica, Martinsried, Germany). The spectrometer is fitted with a transmission grating, providing a high spectral throughput and enabling the record of a whole Raman spectrum simultaneously with a spectral resolution of $\sim 2 \mathrm{~cm}^{-1}$. A 2D Raman map was recorded with a step size of $2 \mu \mathrm{m}$. The data processing of the spectra was performed in Matlab 6.1 (The MathWorks Inc., USA)

Previous studies demonstrated that the diamond morphology and the content and aggregation state of its nitrogen impurities are related to the lithology [19-21]. Re- lying on this information, intragranular diamond included in garnets from representative samples of garnet-biotite gneiss, garnet-zoisite gneiss, carbonate rock (marble) and garnet-clinopyroxene (Grt-Cpx) rock were selected. For these chemically extracted diamonds, representative morphologies for these Kokchetav rocks are shown in Fig. 1. Details on these lithologies, their mineral assemblages and their diamond properties were published elsewhere [17,21,23-25]. Besides these intragranular diamonds, diamonds in Kokchetav rocks might occur intergranular [26]. These intergranular are also included in the present Raman analysis. Almost all Kokchetav diamonds clearly display generally 3-4 and rarely up to 12 concentric zones or sectoring [27]. For the present work, the diamond zoning was investigated by cathodeluminescence (CL) microscopy, under accelerating conditions of $18 \mathrm{kV}$ at the University of Leuven (Belgium). Whether or not this zoning influenced the Raman spectrum, was further checked
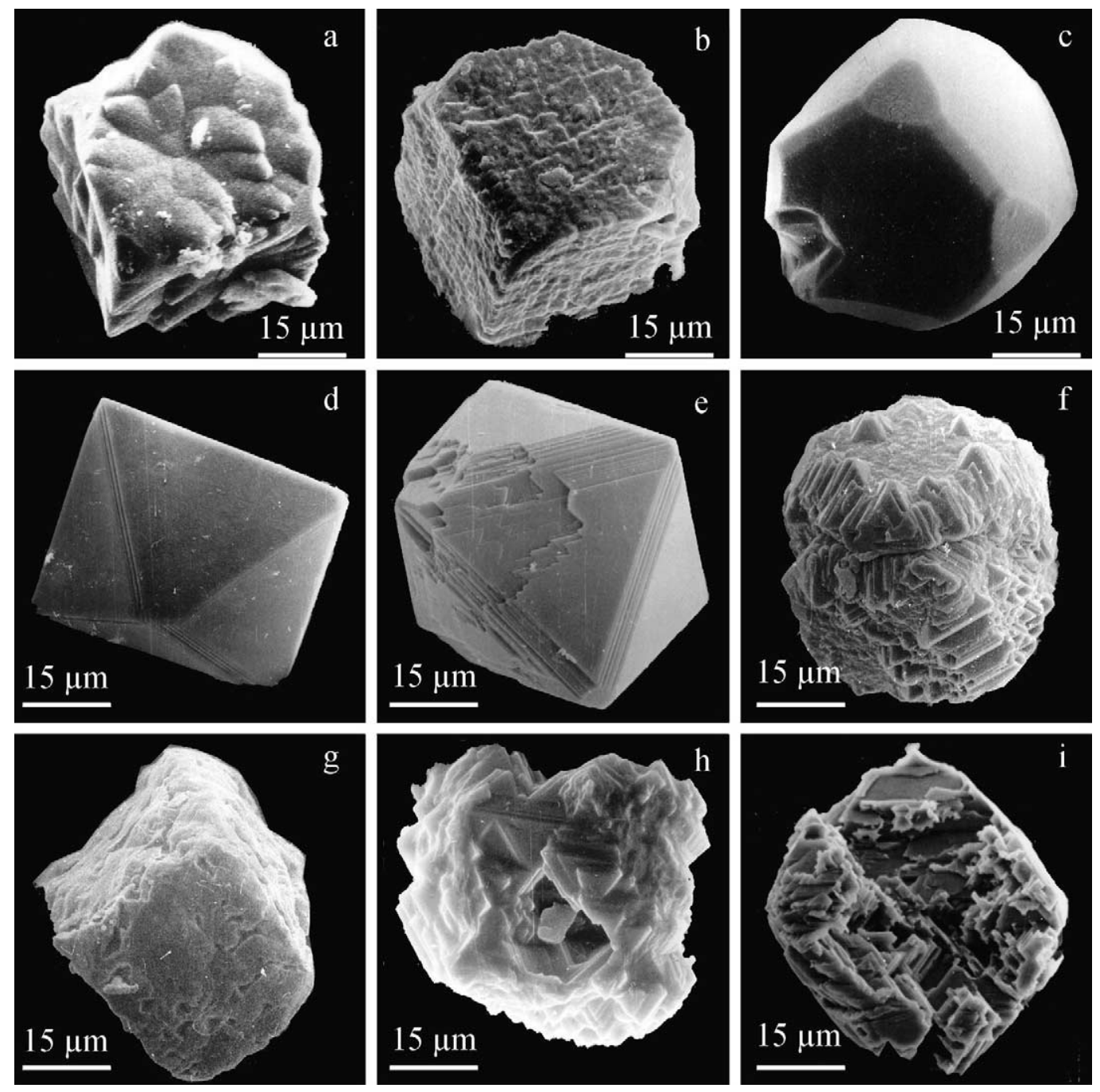

Fig. 1. SEM images of representative metamorphic diamonds from Kokchetav. Biotite gneisses (a and b) cuboids (in G11); (c) cubo-octahedron (in B93-35); zoisite gneisses ( $\mathrm{d}$ and e) octahedrons (in B94-83) and (f) cuboid (in B95-42); carbonate and Grt-Cpx rocks (g and h) cuboid (in G0 and K89-41) and (i) skeleton crystal (in G0). 
by analyzing polished diamonds from garnet-clinopyroxene rocks.

In UHP Kokchetav rocks, garnets are the most common diamond-bearing minerals and only diamonds included in garnets of the different lithologies were investigated. All diamonds were analyzed in situ in polished rock thin sections. In order to avoid problems of contamination, only diamond inclusions that are not exposed at the surface of the polished thin section were analyzed. Thin sections were polished using the technique applied by De Corte [28] for the study of chemically extracted diamond crystals. In that way, the crystal orientation and the position of the diamond within the thin section could be traced.

\section{Results}

More than 40 diamond crystals from different lithologies and provenance areas in the Kokchetav massif (Table 1) were successfully analyzed by means of Raman spectroscopy. Representative Raman spectra for selected diamonds are pre-

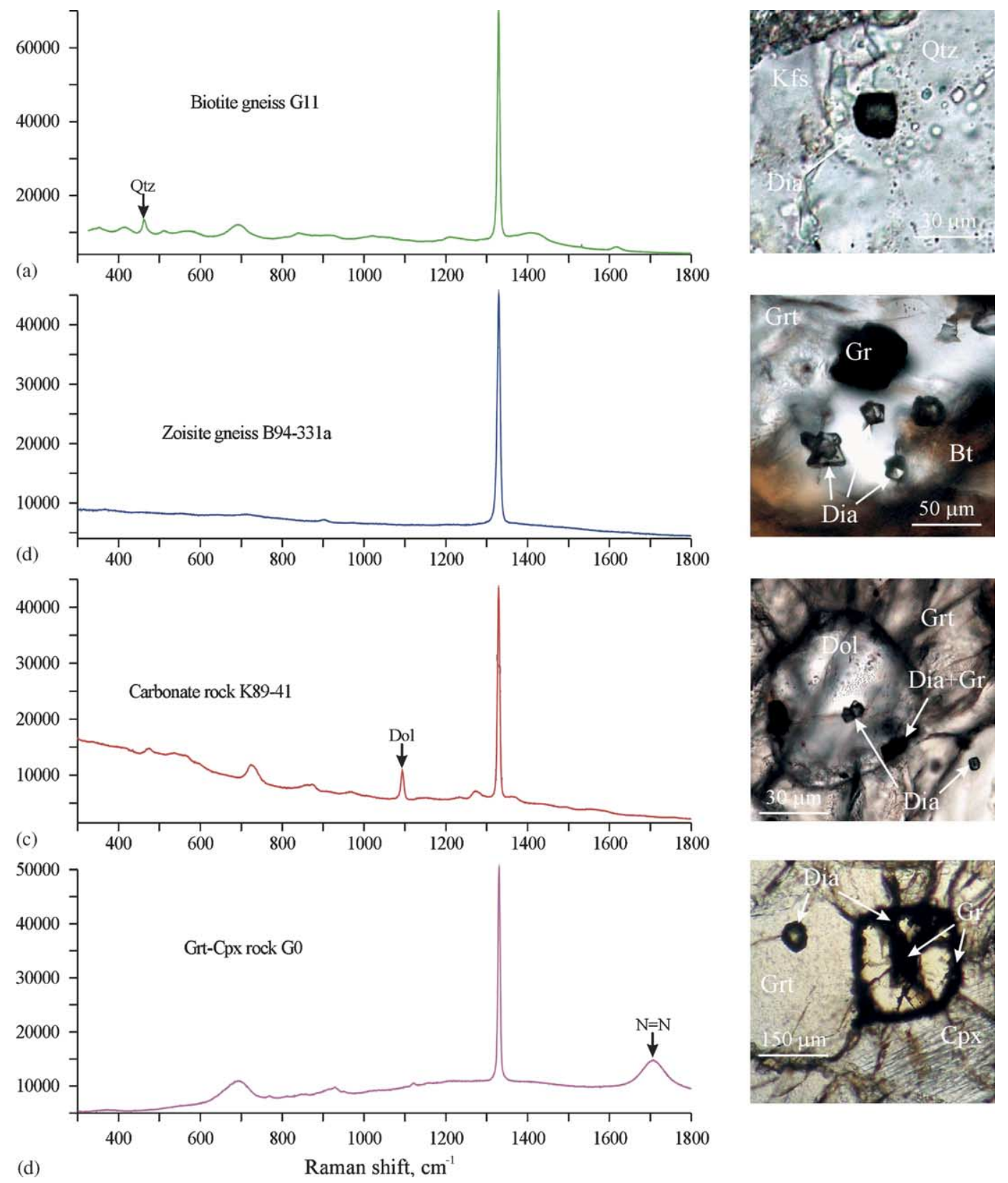

Fig. 2. Raman spectra and microphotographs for diamonds from different lithologies in Kokchetav. The $1330 \mathrm{~cm}^{-1}$ characteristic diamond band is strong in all (a-d) and a broad band occurs near $700 \mathrm{~cm}^{-1}$ in all spectra, but is very weak in (b) the zoisite-gneiss spectrum. Additional bands of quartz and Kfs appear in (a) the spectrum of intergranular diamond in quartzo-feldspatic aggregates of biotite-garget gneiss (G11). Dolomite band is observed in (c) carbonate rock. The $\sim 1700 \mathrm{~cm}^{-1}$ band is exclusive for Grt-Cpx rocks (d) and appears in all its zones (see Figs. 4 and 5). Cpx, clinopyroxene; Grt, garnet; Dia, diamond; Gr, graphite; Dol, dolomite; Qtz, quartz and Kfs, K-feldspar. 
Table 1

Identification and provenance of the investigated microdiamonds

\begin{tabular}{llllr}
\hline Location & Host rock & Sample & \multicolumn{2}{l}{ Diamond } \\
\cline { 3 - 5 } & & & Number of crystals \\
\hline Kumdy-Kol & Grt-Cpx & G0 & 10 & $30-150$ \\
$53^{\circ} 08^{\prime} 10^{\prime \prime} \mathrm{N}$ & Grt-Cpx and Grt-Bt gneiss & G11 & 10 & $11-40$ \\
$68^{\circ} 57^{\prime} 30^{\prime \prime} \mathrm{E}$ & Marble & K89-41 & 5 & $10-30$ \\
Barchi-Kol & Zo-gneiss & B95-29 & 70 \\
$53^{\circ} 09^{\prime} 15^{\prime \prime} \mathrm{N}$ & Zo-gneiss & $114-100$ & 6 & $25-50$ \\
$68^{\circ} 42^{\prime} 20^{\prime \prime} \mathrm{E}$ & Grt-Bt gneiss & B93-35 & 3 & $15-45$ \\
\hline
\end{tabular}
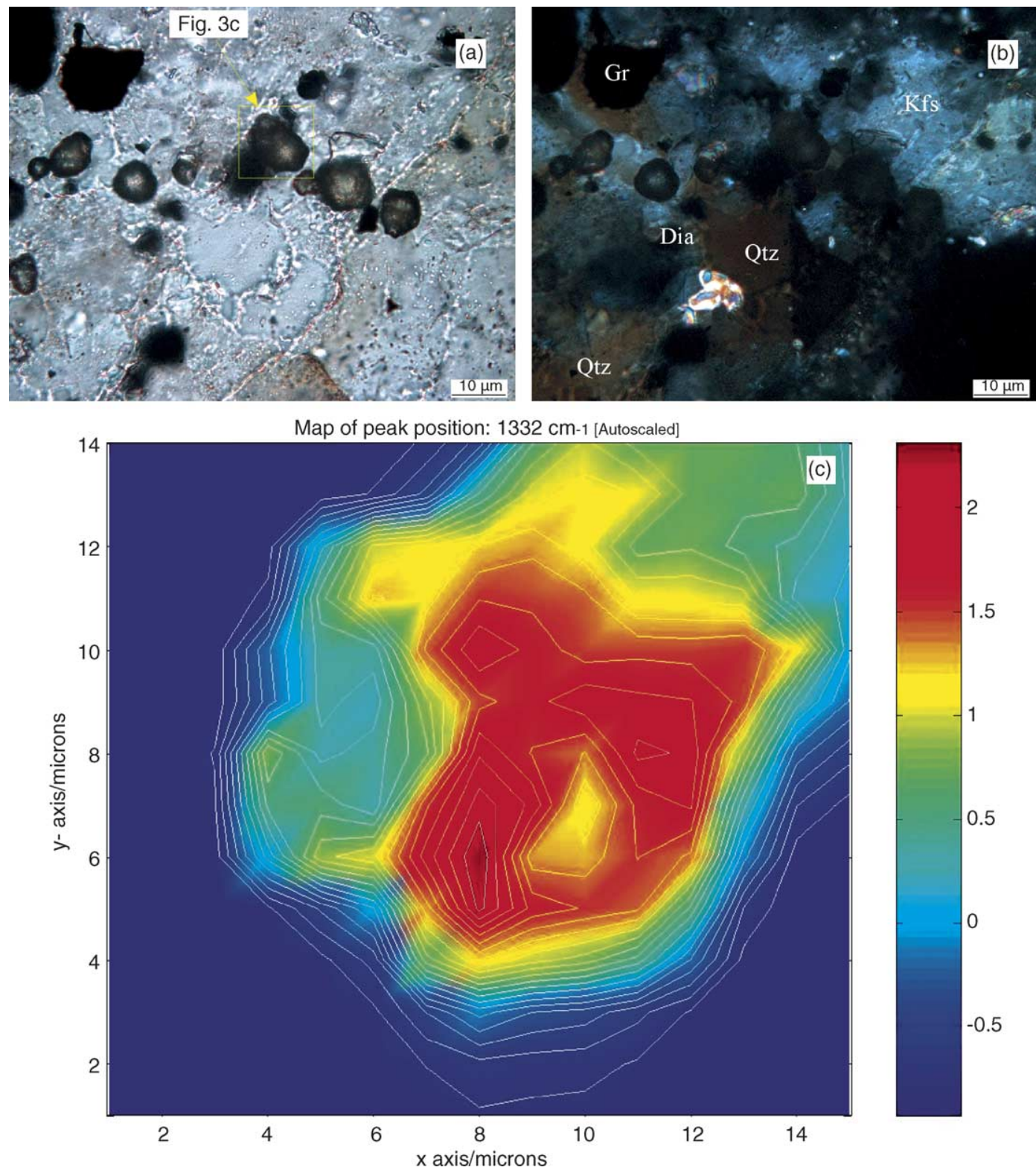

Fig. 3. Intergranular diamond in quartzo-feldspathic aggregate of layered Cpx and Grt-Bt gneiss (G11), (a and b) microphotographs (// and X polarizing nicols). (c) Two-dimensional micro Raman map of the peak position $1332 \mathrm{~cm}^{-1}$ of diamond, as located in (a). 
sented in Fig. 2. Besides the characteristic diamond band, some spectra (samples G11 and G0, Fig. 2) display additional bands that provided valuable information.

\subsection{Garnet-Biotite gneisses}

Korsakov et al. [26] report the side-by-side occurrence of fresh diamond and graphite (Fig. 3a and b) in quartz K-feldspar aggregates within garnet-biotite layers of layered garnet-clinopyroxene biotite gneiss (sample G11) from Kokchetav. The same authors claimed, therefore, that different from intragranular diamond inclusions in UHP minerals, intergranular metamorphic diamond also occurs in Kokchetav.

Cuboids and cubo-octahedral crystals (Fig. 1a-c) are the most typical morphology for diamond crystals of biotite gneisses [18]. This morphology was also shown to be typical for diamonds of the Erzgebirge [15], the Raman spectra of which have been published by Nasdala and Massonne [7].

\subsection{Biotite gneisses}

The Raman spectra for diamonds from biotite gneisses (Fig. 2a) display the characteristic main diamond band at $1330 \mathrm{~cm}^{-1}$. Several additional peaks appear on the spectra but no signal is recorded near band $1700 \mathrm{~cm}$ and any evidence for graphite is lacking no graphite bands 1580 and $1350 \mathrm{~cm}^{-1}$ appear in the spectra of the diamonds. Weakly defined bands are attributable to quartz and K-feldspar. In order to understand the graphite-diamond coexistence, the presence of fluid traces or graphite along the diamond $\mathrm{K}$ feldspar (Kfs) quartz interface in sample G11, was examined by Raman mapping (Fig. 3b). The presence of $\mathrm{H}_{2} \mathrm{O}$ inclusions under high-pressure conditions has a catalytic effect on the diamond graphitization process, while during relatively low temperature experiments $\left(T=1400-1500{ }^{\circ} \mathrm{C}\right.$ and $\left.P=2 \mathrm{GPa}\right)$ up to $30 \mathrm{vol} \%$ of diamond is transformed to graphite after $20 \mathrm{~min}$; the growth rate of graphite is negligibly low after 60 min [29]. The map (Fig. 3b) depicts the peak intensity of the $1330 \mathrm{~cm}^{-1}$ band, covering a $26 \mu \mathrm{m} \times 24 \mu \mathrm{m}$ area by interpolating the set of $14 \times 13$ point analyses. Within the mapped area only characteristic lines of diamond, Kfs and quartz (Qtz) were identified. No traces of a fluid or graphite were found along the interface between the microdiamond and the Qtz-Kfs aggregates (absence of the Raman bands of graphite). The latter feature indicates that intergranular diamond survived during retrograde evolution. The preservation of this type of diamond requires fast exhumation rates, especially in presence of a fluid, i.e. aqueous solution of $\mathrm{CO}_{2}$, often occurring as a fluid inclusion in quartz.

\subsection{Clinozoisite gneisses}

At the current state of research of the Kokchetav massif, this type of rock is the only one containing diamonds with predominantly octahedral morphology $[18,25]$. These microdiamonds also have much lower nitrogen content than the diamonds included in Grt-Cpx rocks [20]. They appear as clean yellow octahedral diamonds and twins (Fig. 2b). Several diamonds from this rock type were chosen for Raman research, only the main diamond band at $1330 \mathrm{~cm}^{-1}$ was observed in all these spectra (Fig. 2b).

\subsection{Carbonate rocks}

Diamonds in the carbonate rocks of Kokchetav are included in garnet, clinopyroxene and zircon [18,20,24] and occur as skeletal crystals or as cuboids (Fig. 1h). In some
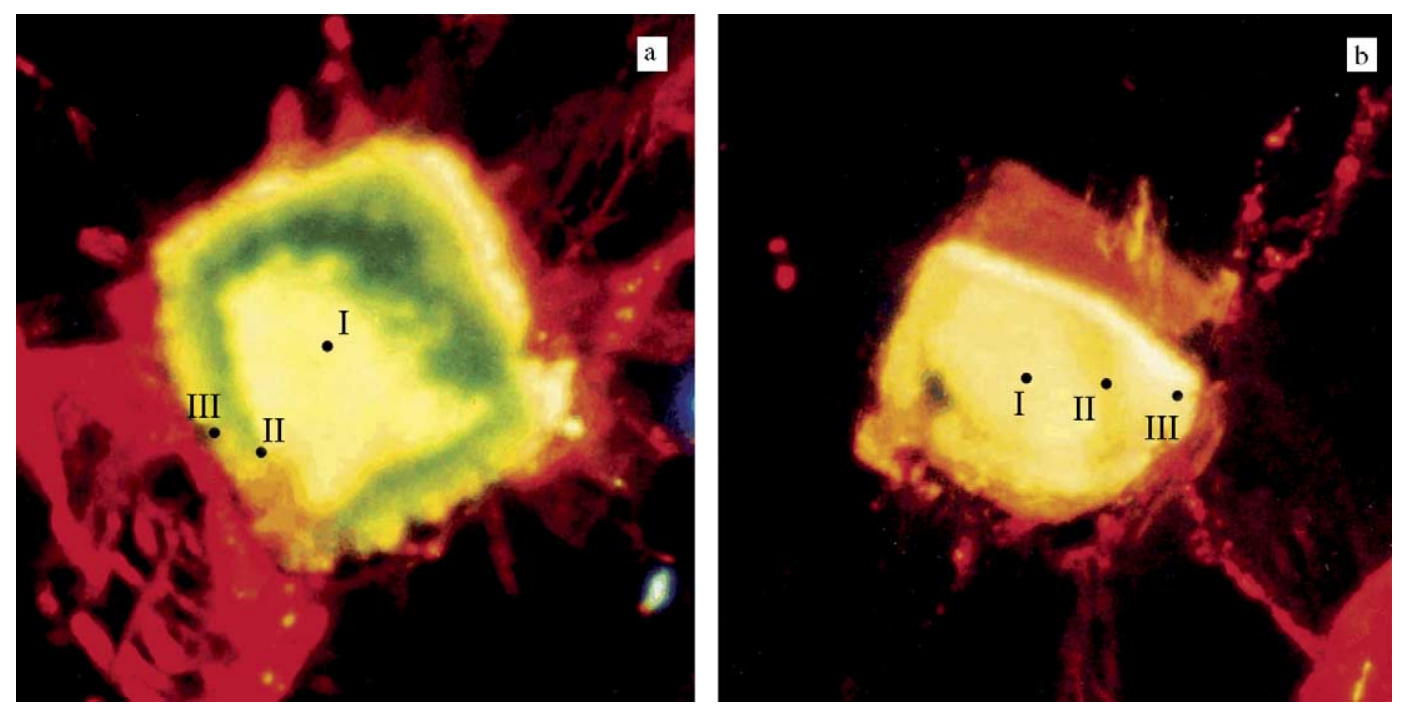

Fig. 4. Internal zonation and Raman spectra of diamond from Grt-Cpx gneiss (G0) (a and b) cathodeluminescence image of diamond. Internal zonation or growth zones parallel to $\{100\}$. Location of Raman point analyses shown (I-III) on Fig. 5. See explanation in the text. 
cases diamond-bearing garnet are themselves included in carbonate.

In the investigated marble sample K89-41 diamonds are included in dolomite or $\mathrm{Mg}$-calcite and are partially or completely covered by graphite (Fig. 2c). This differs from the conclusions of Zhu and Ogasawara [30], who found diamond inclusions only in dolomite, while inclusions in calcite or calcite-dolomite contain only graphite.

Raman spectra (Fig. 2c) from diamonds included in either silicates or carbonates are identical. The main bands of carbonates at 1085 and $1097 \mathrm{~cm}^{-1}$ for calcite and dolomite, respectively, exclusively occur in the Raman spectra collected from diamonds included in carbonates. None of these carbonate fingerprint bands were detected in diamonds in silicate mineral inclusions.

\subsection{Garnet-clinopyroxene rocks}

Diamonds in garnet-clinopyroxene rocks (sample G0) have crystal sizes ranging from 15 to $150 \mu \mathrm{m}$, and in transmitted white light these appear as yellow cuboids (Fig. $1 \mathrm{~g}$ and $\mathrm{h}$ ). In cathodeluminescence, most diamonds display up to four growth zones, parallel to their cuboid faces (Fig. 4a and b). The cores of the largest crystals show a weak and light yellow cathodeluminescence signal with a very bright yellow luminescent boundary between the core and mantle zones. In the latter, the intensity of the signal decreases towards the rim, where weak luminescence is similar to the core zone (Fig. 4a).

The Raman spectra for a diamond from a Grt-Cpx rock (Fig. 2d and Fig. 5) and details (1200-1800 $\left.\mathrm{cm}^{-1}\right)$ in the three

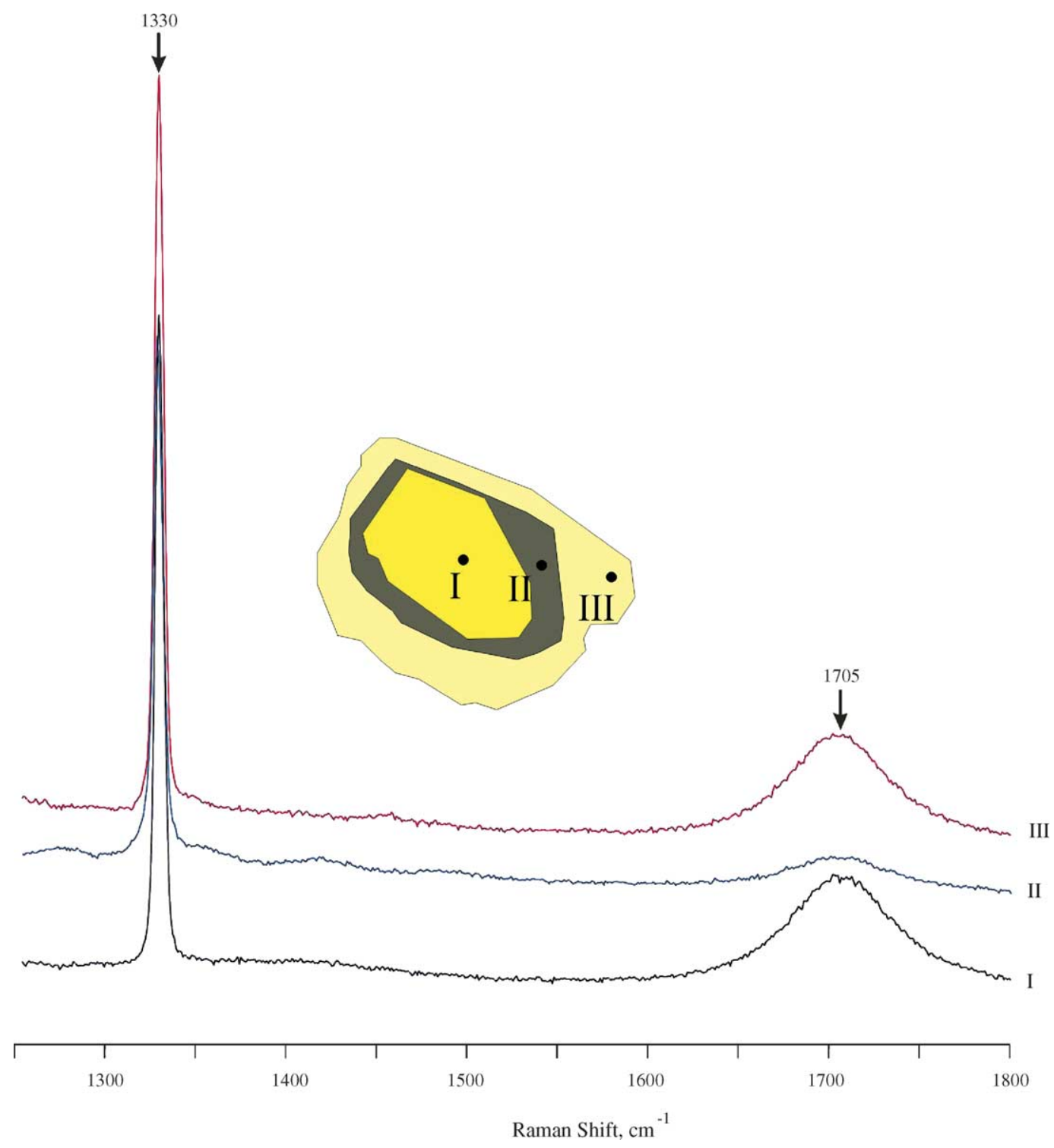

Fig. 5. Raman spectra of different zones (I-III) from a single diamond crystal from Grt-Cpx rock G0. Yellow zones on the CL image (see Fig. 4 have higher Raman intensities (at $1705 \mathrm{~cm}^{-1}$ ) than grayish zone. The $1705 \mathrm{~cm}^{-1}$ band is attributed to the $\mathrm{N}=\mathrm{N}$ stretch vibration. 
zones of CL-zoned diamond are presented in Fig. 4a and b. All spectra display the main diamond band at $1330 \mathrm{~cm}^{-1}$ and a broad band at around $1700 \mathrm{~cm}^{-1}$ for all three zones (Fig. 5). However, the peak intensity of the latter significantly increases from core to rim.

\section{Discussion}

Clearly, the Raman spectra of metamorphic microdiamonds from different lithologies display significant differences (Fig. 2). Laser-induced diamond-to-graphite transformations have been observed in experiments of Nasdala and Massonne [7]. No such phase transformation was observed in our analyses, all performed with a low-power laser $(2 \mathrm{~mW}$ at the sample).

All diamonds yield the characteristic diamond spectrum, which is dominated by a narrow intense band observed at $1328-1331 \mathrm{~cm}^{-1}$. Ideally, the peak of diamond is $1332 \mathrm{~cm}^{-1}$ [31], whereas in our experiments the peak observed is slightly shifted to $1330-1328 \mathrm{~cm}^{-1}$. The wave number of the Raman-active mode can be shifted toward lower values (down to $1310 \mathrm{~cm}^{-1}$ ) if the laser power used for exciting the Raman effect is increased. Zhao et al. [32] have shown that such a shift can also be achieved by decreasing the grain size of diamond crystallites down to a few tens of nanometers. But it is not the case in our experiments. We do not observe any relation between the diamond size and the width and peak position of the main Raman line at $1332 \mathrm{~cm}^{-1}$. An alternative explanation was proposed by Godard et al. [33]. They explain the shift of the main diamond bands by diamond metamictization or disordering. Our experiments do not support this suggestion.

In this study, the broad band at $\sim 1700 \mathrm{~cm}^{-1}$ (Figs. $2 \mathrm{~d}$ and 5) was exclusively observed in the diamonds from garnet-clinopyroxene rocks. A broad band at $\sim 1730 \mathrm{~cm}^{-1}$ was observed by Gogotsi et al. [34] in diamond after indentation and was attributed to $\mathrm{C}=\mathrm{O}$ stretching. The presence of this band is the result of a reaction between diamond and air. Comparing this band with our spectra, we can conclude that there is clearly an offset of about $50 \mathrm{~cm}^{-1}$ with the $\mathrm{C}=\mathrm{O}$ peak; the Raman band which is reported here is at a different position and is much broader. Among all different diamond types, diamonds from garnet-pyroxene rocks were shown to bear up to $11,000 \mathrm{ppm}$ of nitrogen, the highest amount recorded [19-21]. The $1700 \mathrm{~cm}^{-1}$ band may be associated with the very high content of double bounded $\mathrm{N}=\mathrm{N}$ or $\mathrm{N}=\mathrm{C}$ groups $[35,36]$. De Corte et al. [19] classified these diamonds as Ib-Ia types and suggested that nitrogen is incorporated in the diamond lattice as single atoms (carbon defect) or pairs of nitrogen atoms [37-39]. However, a significant quantity of nitrogen (up to $7000 \mathrm{ppm}$ ) has been found as an infrared-inactive form and may represent fluid inclusions [21], where nitrogen occurs as $\mathrm{N}_{2}$ fluids and not as platelet defects $[20,21]$. This tends to suggest that the presence of this $\sim 1700 \mathrm{~cm}^{-1}$ Raman band may be assigned to the presence of $\mathrm{N}_{2}$-fluid inclusions with an average size of less than $1 \mu \mathrm{m}[35,36]$. This suggestion may be further supported by differences in intensity of the $1705 \mathrm{~cm}^{-1}$ band within the different zones of a single diamond crystal (Fig. 5), and is moreover in agreement with previous observations [27]. There is a positive correlation between the intensity of the CL signal and $1705 \mathrm{~cm}^{-1}$ band. Yellow zones on the CL image (Fig. 4b) correspond with higher Raman intensities $\left(1705 \mathrm{~cm}^{-1}\right)$ than grayish zones. Fig. 5 indicates that the presence of nitrogen defects causes the appearance of this band. Further investigations of such diamond crystals with modern electron microprobes (such as the Cameca SX100) are able to detect nitrogen at concentrations of 11,000 ppm are required and would be very helpful to confirm this suggestion.

\section{Conclusions}

The aim of this study was to provide the first Ramanspectroscopic based classification of metamorphic diamonds from different lithologies of the Kokchetav massif. The second aim has been to examine whether such Raman spectroscopic study is suitable for the discrimination of different populations of microdiamonds in ultrahigh-pressure research. In conclusion, the following points can be mentioned.

i. Evidence of carbonate inclusions is lacking in all diamond spectra.

ii. No relation exists between diamond peak intensity and crystal size.

iii. All Raman spectra of diamonds from different lithologies bear a narrow and intense band between 1328 and $1331\left(1330 \mathrm{~cm}^{-1}\right.$ peak) representing the $\mathrm{C}-\mathrm{C}$ symmetric stretch vibration in diamond. Additional peaks, appearing in some spectra, could be attributed to other minerals (adjacent or included in diamond).

iv. A broad band at $\sim 1700 \mathrm{~cm}^{-1}$ occurs exclusively in diamond spectra from Grt-Cpx rocks. As sub-micron fluid $\mathrm{N}_{2}$ inclusions in the diamond, double bounded nitrogen is supposed to be responsible for this band. The peak intensity may roughly indicate the content of the inclusions in diamonds. In contrast to FTIR spectroscopy this information can be obtained in situ (within a thin section).

v. In addition to FTIR, Raman spectroscopy is a good tool for the discrimination between distinct diamond populations from different lithologies.

vi. Even a very thin graphite coating $(\sim 100 \mathrm{~nm})$ makes the diamond undetectable by Raman studies performed with laser wavelength $785 \mathrm{~nm}$, as used here. Therefore, cubic shaped graphite inclusions from high- to ultrahigh-pressure rocks need more attention, in order to avoid overlooking coated diamonds, as an UHPM indicator. 


\section{Acknowledgments}

The authors acknowledge the referees and editors who helped to improve the paper. We thank R. Swennen (KUL, Belgium) for kindfully providing analytical facilities. The authors wish to thank the Fund for Scientific Research Flanders (FWO, Vlaanderen) for the financial support and P.V. is especially grateful to the Fund for Scientific Research Flanders (FWO, Vlaanderen) for his postdoctoral fellowship. A.K. acknowledges the Belgian Office for Scientific, Technical and Cultural Collaboration for his postdoctoral fellowship at the Royal Museum of Central Africa, Belgium. Kaiser and Toptica are acknowledged for providing access to the instrumentation with mapping ability, during a training session. This work was financially supported by the Russian Foundation for Basic Research (04-05-64360-a)

\section{References}

[1] D.R. Gage, S.O. Farwell, Anal. Chem. 53 (1981) 2123.

[2] N.V. Sobolev, V.S. Shatsky, M.A. Vavilov, S.V. Goryainov, Doklady Akademii Nauk SSSR 321 (1991) 184.

[3] N.V. Sobolev, V.S. Shatsky, M.A. Vavilov, S.V. Goryainov, Doklady Akademii Nauk SSSR 334 (1994) 488.

[4] I. Katayama, A.A. Zayachkovsky, S. Maruyama, Isl. Arc 9 (2000) 417.

[5] C.D. Parkinson, I. Katayama, Geology 27 (1999) 979.

[6] C.D. Parkinson, Lithos 52 (2000) 215.

[7] L. Nasdala, H.-J. Massonne, Eur. J. Miner. 12 (2000) 495.

[8] H. Ishida, Y. Ogasawara, K. Ohsumi, A. Saito, J. Metamorphic Geol. 21 (2003) 515.

[9] H.L.M. van Roermund, D.A. Carswell, M.R. Drury, T.C. Heijboer, Geology 30 (2002) 959.

[10] H. Boppart, J. van Straaten, I.F. Silvera, Phys. Rev. B 32 (1985) 1423.

[11] H.-J. Massonne, L. Nasdala, Am. Mineralogist 88 (2003) 883.

[12] S.K. Sharma, H.-K. Mao, P.M. Bell, J.A. Xu, J. Raman Spectrosc. 16 (1985) 350.

[13] M. Yoshikawa, Y. Mori, H. Obata, M. Maegawa, G. Katagiri, H. Ishida, A. Ishitani, Appl. Phys. Lett. 67 (1995) 6946.

[14] P.J. O'Brien, N. Zotov, R. Law, M.A. Khan, M.Q. Jan, Geology 29 (2001) 435.

[15] H.-J. Massonne, Proceedings of Seventh International Kimberlite Conference, vol. 2, 1999, p. 533.
[16] O.M. Rozen, Y.M. Zorin, A.A. Zayachkovsky, Doklady Akademii Nauk SSSR 203 (1972) 674

[17] N.V. Sobolev, V.S. Shatsky, Nature 343 (1990) 742.

[18] V.S. Shatsky, G.M. Rylov, E.S. Efimova, K. De Corte, N.V. Sobolev, Geologiya i Geofizika 39 (1998) 942.

[19] K. De Corte, P. Cartigny, V.S. Shatsky, N.V. Sobolev, M. Javoy, Geochim. Cosmochim. Acta 62 (1998) 3765.

[20] K. De Corte, A. Korsakov, W. Taylor, P. Cartigny, M. Ader, P.D. Paepe, Isl. Arc 9 (2000) 284.

[21] P. Cartigny, K. De Corte, V.S. Shatsky, M. Ader, P. De Paepe, N.V. Sobolev, M. Javoy, Chem. Geol. 176 (2001) 265.

[22] J. Yang, Z. Xu, L.F. Dobrzhinetskaya, H.W. Green, X. Pei, R. Shi, C. Wu, J.L. Wooden, J. Zhang, Y. Wan, H. Li, Terra Nova 15 (2003) 370.

[23] V.S. Shatsky, N.V. Sobolev, M.A. Vavilov, in: R.G. Coleman, X. Wang (Eds.), Ultrahigh Pressure Metamorphism, Cambridge University Press, Cambridge, 1995, p. 427.

[24] Y. Ogasawara, M. Ohta, K. Fukasawa, I. Katayama, S. Maruyama, Isl. Arc 9 (2000) 400.

[25] A.V. Korsakov, V.S. Shatsky, N.V. Sobolev, A.A. Zayachkovsky, Eur. J. Mineralogy 14 (2002) 915.

[26] A.V. Korsakov, K. Theunissen, L.V. Smirnova, Terra Nova 16 (2004) 146.

[27] K. De Corte, W.R. Taylor, P. De Paepe, in: C.D. Parkinson, I. Katayama, J.G. Liou, S. Maruyama (Eds.), The Diamond-bearing Kokchetav Massif, Kazakhstan, Universal Academy Press, Inc., Tokyo, Japan, 2002, p. 115.

[28] K. De Corte, Study of Microdiamonds from UHP Metamorphic Rocks of the Kokchetav Massif (Northern Kazakhstan): Characterisation and Genesis, Ph.D. Thesis, Universiteit Gent, 2000.

[29] J. Qian, C. Pantea, G.A. Voronin, T.W. Zerda, J. Appl. Phys. 90 (2001) 1632.

[30] Y.F. Zhu, Y. Ogasawara, Geology 30 (2002) 947.

[31] O. Madelung, Semiconductors. Group IV elements and III-IV compounds Data in Science and Technology, Springer, Berlin, New York, 1991.

[32] X.-Z. Zhao, K.A. Cherian, R. Roy, W.B. White, J. Mater. Res. 13 (1998) 1974.

[33] G. Godard, D. Smith, M. Moreau, Abstract Volume of 32nd International Geological Congress, Florence, 2004

[34] Y.G. Gogotsi, A. Kailer, K. Nickel, J. Appl. Phys. 84 (1998) 1299.

[35] D. Lin-Vien, N.B. Colthup, W.G. Fateley, J.G. Grasselli, The Handbook of Infrared and Raman Characteristic Frequencies of Organic Molecules, Academic Press, San Diego, 1991.

[36] G. Socrates, Infrared and Raman Characteristic Group Frequencies, third ed., John Wiley \& Sons Inc., New York, 2001.

[37] G. Davies, J. Phys. C: Solid State Phys. 9 (1976) 537.

[38] G.S. Woods, Philos. Mag. 34 (1976) 993.

[39] R. Jones, P. Briddon, S. Oberg, Philos. Mag. Lett. 66 (1992) 67. 